\title{
PRELIMINARY RESULTS UPON CRYSTALLIZATION OF THE CALCITE-SPHEROCOBALTITE SOLID SOLUTION
}

\author{
Katsikopoulos D. ${ }^{1}$, González-Fernández Á. ${ }^{1}$, and Prieto M. ${ }^{1}$ \\ ${ }^{1}$ Departamento de Geología, Universidad de Oviedo, Jesús Aria de Velasco, s/n, 33005 Oviedo, \\ Spain
}

\begin{abstract}
The (Ca, Co $\mathrm{CO}_{3}-\mathrm{H}_{2} \mathrm{O}$ system was studied at $25{ }^{\circ} \mathrm{C}$ using both precipitation experiments and crystallization in silica gel in order to examine the thermodynamic properties and crystallization of the solid solution. Near the $\mathrm{CaCO}_{3}$ endmember, unit cell parameters and volume of the solid phase show an almost linear variation, while near the $\mathrm{CoCO}_{3}$ endmember, the growth of a phase of low crystallinity prevented those calculations. A detailed Fourier Transform Infrared Spectroscopy (FTIR) assigned this phase to a cobalt carbonate hydrate $\left(\mathrm{CoCO}_{3} \cdot \mathrm{nH}_{2} \mathrm{O}\right)$. The fact that cell volumes are plotted above the line that corresponds to the theoretical cell volumes of the two endmembers, indicates positive value of excess volume of mixing $\left(V^{E}\right)$, and consequently a non-ideal solid solution. Nucleation under conditions of high supersaturation in gels showed that in all the cases the degree of cobalt incorporation in crystals was low with an average value of cobalt mole fraction $\left(\mathrm{XCoCO}_{3}\right)$ around 0.03 while -even in the Co-rich zones-this value never exceeded the upper limit of 0.2. Crystal morphologies also exhibited a wide variety of forms as a function of aqueous phase composition.
\end{abstract}

Key words: solid solution, diffusion, crystal growth, free volume of mixing.

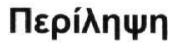

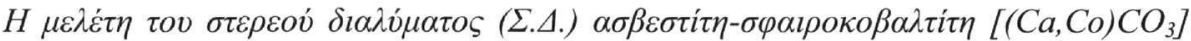

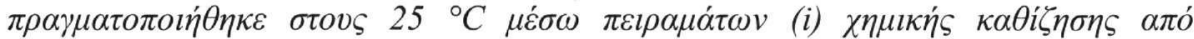

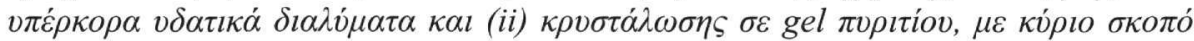

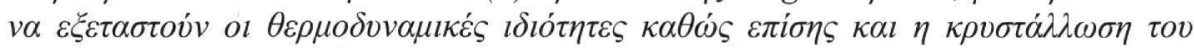

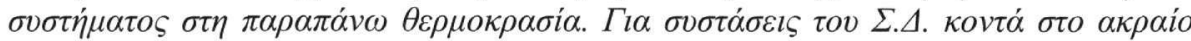

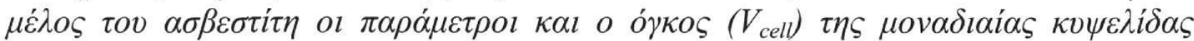

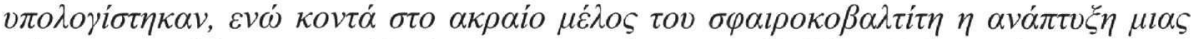

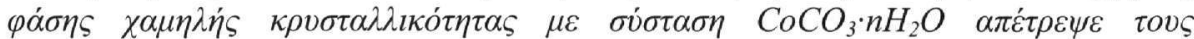

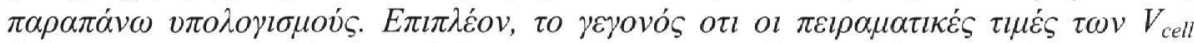

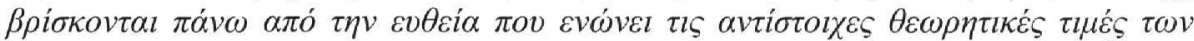

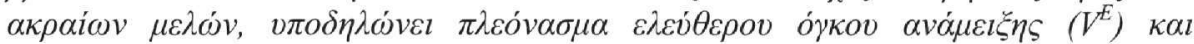

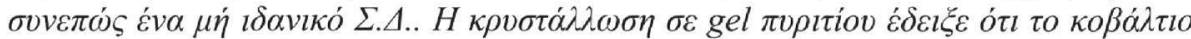

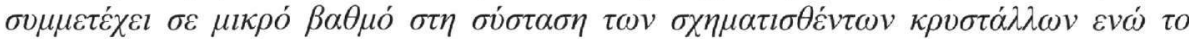

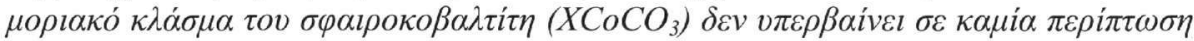

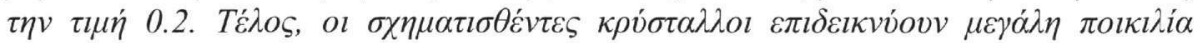

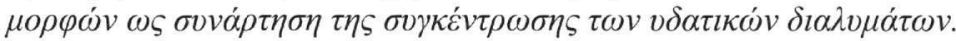

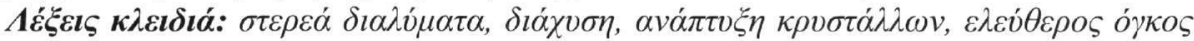
$\alpha \nu \alpha ́ \mu \varepsilon l \xi ̈ \eta \varsigma$. 


\section{Introduction}

As calcite is one of the most abundant carbonate minerals on Earth, and cobalt a toxic metal (Lauwerys et al. 1994), the study of the $(\mathrm{Ca}, \mathrm{Co}) \mathrm{CO}_{3}$ solid solution is of high importance. Although there are different works published, referring to morphological modification of calcite crystals doped by cobalt (Fernández-Díaz et al. 2006, Braybrook et al. 2002), or to calcite growth and dissolution in the presence of dissolved cobalt (Freij et al. 2004), the solid solution is not fully studied yet. The only available thermodynamic data comes from Goldsmith and Northop (Goldsmith et al. 1965) who studied the ternary system $\mathrm{CaCO}_{3}-\mathrm{MgCO}_{3}-\mathrm{CoCO}_{3}$ by delimiting basic relations at $600-750{ }^{\circ} \mathrm{C}$ and 15 kilobars.

In this work, the interaction of $\mathrm{Co}(2+)$ with calcite is investigated, having as main intentions to characterize the solid solution (ideal or non-ideal), to evaluate the way in which composition at nucleation depends on supersaturation, and finally to examine the chemical and morphological evolution of crystals during growth.

\section{Experimental Methods}

\subsection{Precipitation Experiments}

Small crystals of the $(\mathrm{Ca}, \mathrm{Co}) \mathrm{CO}_{3}$ solid solution were precipitated according to the following reaction:

$\mathrm{Na}_{2} \mathrm{CO}_{3}(\mathrm{aq})+\mathrm{xCoCl}_{2}(\mathrm{aq})+(1-\mathrm{x}) \mathrm{CaCl}_{2}(\mathrm{aq}) \Leftrightarrow \mathrm{Co}_{\mathrm{x}} \mathrm{Ca}_{(1-\mathrm{x})} \mathrm{CO}_{3}(\mathrm{~s})+2 \mathrm{Na}^{+}(\mathrm{aq})+2 \mathrm{Cl}^{-}(\mathrm{aq})$

In order to achieve precipitation of different compositions of the solid solution, $50 \mathrm{ml}$ of solutions with different ratios of $\mathrm{CaCl}_{2}$ and $\mathrm{CoCl}_{2}$ (Table 1) were used. The mother solutions were added in a vessel that contained $50 \mathrm{ml}$ of a continuously stirred solution of $0.05 \mathrm{M} \mathrm{Na}_{2} \mathrm{CO}_{3}$. The precipitates were then separated from the solution using a filter and dried in an oven at approximately $39{ }^{\circ} \mathrm{C}$. By using adhesive carbon tape, a small quantity of crystals was taken from each precipitate and mounted on an aluminium sample holder. Finally all the samples were covered with carbon. The rest of the precipitates were powdered so they could be examined by X-ray powder diffraction.

Table 1 - Initial concentration of reactants used in precipitation experiments. $\mathrm{Na}_{2} \mathrm{CO}_{3}$ concentration in all the experiments was 0.05 moles/lt

\begin{tabular}{|c|c|c|c|}
\hline experiment & $\mathbf{C a C l}_{\mathbf{2}}(\mathbf{M})$ & $\mathbf{C o C l}_{\mathbf{2}}(\mathbf{M})$ & $\mathbf{C a}^{2+} / \mathbf{C o}^{2+}$ \\
\hline P-1 & 0.05 & 0 & Ca \\
\hline P-2 & 0.05 & 0.001 & $50: 1$ \\
\hline P-3 & 0.05 & 0.003 & $17: 1$ \\
\hline P-4 & 0.05 & 0.005 & $10: 1$ \\
\hline P-5 & 0.05 & 0.007 & $7: 1$ \\
\hline P-6 & 0.05 & 0.01 & $5: 1$ \\
\hline P-7 & 0.05 & 0.02 & $5: 2$ \\
\hline P-8 & 0.05 & 0.03 & $5: 3$ \\
\hline P-9 & 0.05 & 0.05 & 1 \\
\hline P-10 & 0.03 & 0.05 & $3: 5$ \\
\hline P-11 & 0.01 & 0.05 & $1: 5$ \\
\hline P-12 & 0 & 0.05 & Co \\
\hline
\end{tabular}

Crystal phases precipitated were characterized by X-ray powder diffraction analysis that was carried out on a Philips X'Pert Pro X-ray diffractometer in the $2 \theta$ angle range between $5^{\circ}$ to $80^{\circ}$ in 
steps of $0.02^{\circ}$ using $\mathrm{Cu} \mathrm{K} \alpha$ radiation. The study of the main reflections of diffractograms and the calculation of the unit cell parameters of each precipitate was made using the computer program X'Pert Plus. Characterization of low-crystallinity phases achieved by Fourier Transform Infrared Spectroscopy (FTIR) carried out on a Jobin-Yvon Horiba 800 UV LabRam-HR spectrometer equipped with a liquid nitrogen-cooled detector. A Golden Gate ATR Mk II modified attenuated total reflection system was also used. The spectral region spanned from 4000 to $600 \mathrm{~cm}^{-1}$ with a resolution of $4 \mathrm{~cm}^{-1}$. Experimental results were then compared to the spectra of (i) a natural calcite (Island Spar), and (ii) a commercial $\mathrm{CoCO}_{3} \cdot \mathrm{Co}(\mathrm{OH})_{2} \cdot \mathrm{nH}_{2} \mathrm{O}$ substance.

\subsection{Crystallization in Gels}

In that group of experiments the reactants were introduced in two vertical reservoirs separated by a column of silica hydrogel, which occupied the horizontal branch between them, constituting in such a way a double diffusion system (U-tube), as shown in Figure 1. The silica gel was prepared by acidification of a $\mathrm{Na}_{2} \mathrm{SiO}_{3}$ solution (Merck, sp. gr.: $1.059 \mathrm{~g} / \mathrm{cm}^{3}$ ) with $\mathrm{HCl}(1 \mathrm{~N})$ until a $\mathrm{pH}=5.5$ was obtained. The gel -due to polymerization- behaves as a porous medium (Dullien 1979), suppresses convection and advection of the reactants, which can only move through the gel, and eventually mix in a column profile by molecular diffusion. Because of the physical and chemical properties of the gel (micron-sized pores, $95.6 \mathrm{wt} \%$ "effective water" (Prieto et al. 2002)), the nucleation density decreases and consequently larger crystallite form. Three sets of experiments were carried out, using tubes with different lengths (Table 2), and parent solutions with different initial concentrations. In all cases one reactant reservoir contained $8 \mathrm{ml}$ of $0.5 \mathrm{M} \mathrm{Na}_{2} \mathrm{CO}_{3}$ and the other $8 \mathrm{ml}$ of mother solutions with different ratios of $\mathrm{CaCl}_{2}$ and $\mathrm{CoCl}_{2}$ (Table 3).

Table 2 - Length of tubes used in the experiments and length of gel column in the horizontal branch

\begin{tabular}{|c|c|c|}
\hline Exp. & $\begin{array}{c}\text { tube characterization } \\
\text { and length }(\mathbf{c m})\end{array}$ & $\begin{array}{c}\text { gel column } \\
\text { length }(\mathbf{c m})\end{array}$ \\
\hline S1-S10 & Small: 15 & $7-8$ \\
\hline I1-I10 & Intermediate: 25.7 & $16-17$ \\
\hline L1-L10 & Large: 35 & $26-28$ \\
\hline
\end{tabular}

Table 3 - Initial concentrations of reactants used in gel experiments. $\mathrm{Na}_{2} \mathrm{CO}_{3}$ concentration in all the experiments is $\mathbf{0 . 5}$ moles/lt. Total waiting period until nucleation and distance of primary nucleation zone measured from the side of cations are also shown

\begin{tabular}{|c|c|c|c|c|c|c|c|}
\hline \multicolumn{2}{|c|}{ initial concentrations } & \multicolumn{2}{c|}{$\begin{array}{c}\text { small } \\
\text { U-tubes set }\end{array}$} & \multicolumn{2}{c|}{$\begin{array}{c}\text { int/diate } \\
\text { U-tubes set }\end{array}$} & \multicolumn{2}{c|}{$\begin{array}{c}\text { large } \\
\text { U-tubes set }\end{array}$} \\
\hline $\mathbf{C a C l}_{\mathbf{2}}(\mathbf{M})$ & $\mathbf{C o C l}_{\mathbf{2}} \mathbf{( M )}$ & $\mathbf{t}_{\mathbf{w}}(\mathbf{h})$ & position(cm) & $\mathbf{t}_{\mathbf{w}}(\mathbf{h})$ & position(cm) & $\mathbf{t}_{\mathbf{w}} \mathbf{( h )}$ & position(cm) \\
\hline 0.5 & 0 & 46 & 4 & 231 & 10.5 & 527 & 18 \\
\hline 0.5 & 0.01 & 70 & 5 & 212 & 11 & 550 & 16.5 \\
\hline 0.5 & 0.03 & 66 & 5 & 212 & 10 & 549 & 17 \\
\hline 0.5 & 0.05 & 40 & 4 & 212 & 10 & 646 & 18.5 \\
\hline 0.5 & 0.1 & 43 & 4 & 219 & 11 & 550 & 17 \\
\hline 0.5 & 0.3 & 47 & 4.5 & 233 & 11 & 544 & 17.5 \\
\hline 0.5 & 0.5 & 50 & 4.5 & 218 & 11 & 688 & 19.5 \\
\hline 0.3 & 0.5 & 50 & 4.5 & 231 & 11 & 691 & 19.5 \\
\hline 0.1 & 0.5 & 50 & 4 & 262 & 10.5 & 520 & 17 \\
\hline 0 & 0.5 & \multicolumn{2}{|c|}{ no crystal phase } & no crystal phase & no crystal phase \\
\hline
\end{tabular}

All experiments were stored in a constant temperature cabinet at $25 \pm 0.1{ }^{\circ} \mathrm{C}$. The growth evolution of the crystals and the position in the gel column of the first nuclei (visible at x 500 
magnification) were then monitored. The total waiting period $t_{w}$, from the beginning of the experiment, until the first crystallites appeared was noted, and the position of the nucleation area was measured (Table 3). The experiments were stopped two months after nucleation observed in the intermediate and small U-tubes, and one month after nucleation observed in the large U-tubes. The crystals were finally recovered by dissolving the gel in a $1 \mathrm{M} \mathrm{NaOH}$ solution.

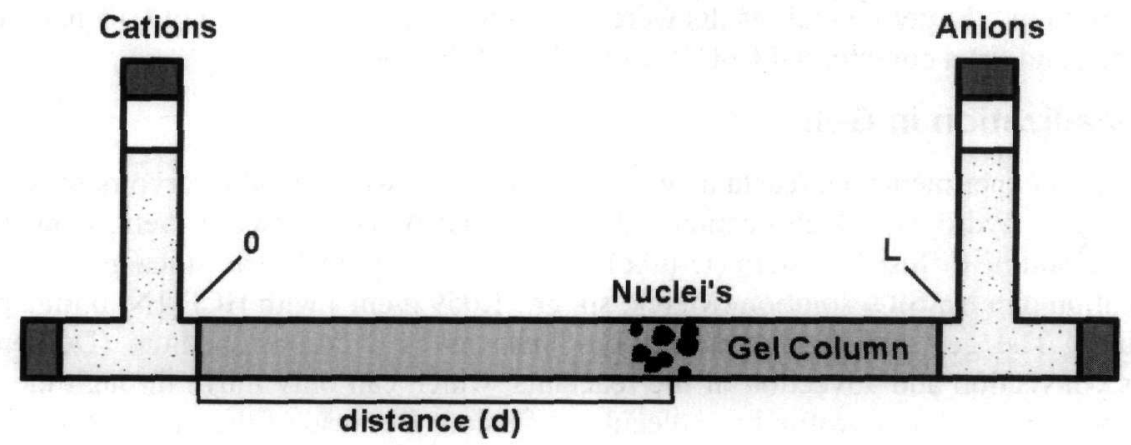

Figure 1 - A double diffusion system arrangement used in the gel experiments. The solutions that contained different ratios of $\mathrm{Ca}^{2+}$ and $\mathrm{Co}^{2+}$ were introduced in the "cations" side reservoir while the $\mathrm{Na}_{2} \mathrm{CO}_{3}$ solutions in the "anions" side

The total concentrations of the reactants through different profiles of the gel column were calculated using a one-dimensional algorithm (Henisch et al. 1986) suitable for diffusion in finite systems:

Equation 1 - Concentrations through the gel column

$$
C(d, t+\Delta t)=\frac{1}{6}[C(d-\Delta d, t)+4 C(d, t)+C(d+\Delta d, t)]
$$

where $C$ is the concentration, $d$ is the position in the silica gel column, $t$ is the diffusion time. This equation is valid when $\Delta t$ is chosen to be related to $\Delta d$ by:

Equation 2 - Relation between time and position intervals in Equation 1

$$
\Delta t=\frac{1}{6 D_{w} \frac{\phi}{\tau^{2}}} \Delta d^{2}
$$

where $D_{w}$ is the diffusion coefficient of the reactant in water, $\phi$ is the porosity, and $\tau$ the effective tortuosity of the gel (Lichtner et al. 1996). The characteristics of the silica gel are $\phi=0.969$ and $\tau=1.19$ (Andara 2004). The diffusion coefficients of the reactants $\mathrm{Na}_{2} \mathrm{CO}_{3}, \mathrm{CaCl}_{2}$, and $\mathrm{CoCl}_{2}$ in water $\left(D_{w}\right.$ ) were calculated and found $1.193 \times 10^{-5}, 1.336 \times 10^{-5}$, and $1.227 \times 10^{-5} \mathrm{~cm}^{2} \mathrm{~s}^{-}$ ${ }^{1}$, respectively (Robinson et al. 1959). In that way, the total concentrations of the three reactants were calculated at $t=t_{w}$ for the nucleation zone in the gel column, and the solution's speciation was made using PHREEQC v2.12.5.669. 


\section{Results and Discussion}

\subsection{Precipitation Experiments}

An X-ray powder diffraction analysis carried out for precipitation experiments showed the growth of a phase of low crystallinity from aqueous solutions high in cobalt (Fig. 2). This phase dominates in the precipitates preventing the definition of unit cell parameters from the corresponding diffractograms (Fig. 3). In order to reduce the spread of the low-crystallinity phase, all sequence of experiments repeated using $\mathrm{NaHCO}_{3}$ instead of $\mathrm{Na}_{2} \mathrm{CO}_{3}$ as a reactant, but also in that case, the degree of crystallinity from aqueous solutions high in cobalt was proved very low. Moreover, precipitation experiments of the $(\mathrm{Ca}, \mathrm{Co}) \mathrm{CO}_{3}$ solid solution were carried out in the atmosphere of $\mathrm{N}_{2}$, using the same reactants, and initial concentrations as previous, but the diffraction analysis of those samples showed that the growth of the low-crystallinity phase could not be prevented. Therefore, all experimental procedures in the author's knowledge are resulting to the suggestion that although it is achievable to obtain precipitation of spherocobaltite at hydrothermal conditions, mainly through autoclave techniques (Gamsjager et al. 1980, Egorov et al. 1976, Ikornikova et al. $1975)$, it is not possible to precipitate cobalt carbonate $\left(\mathrm{CoCO}_{3}\right)$ at room temperature $\left(25^{\circ} \mathrm{C}\right)$ and pressure (1 Atm).
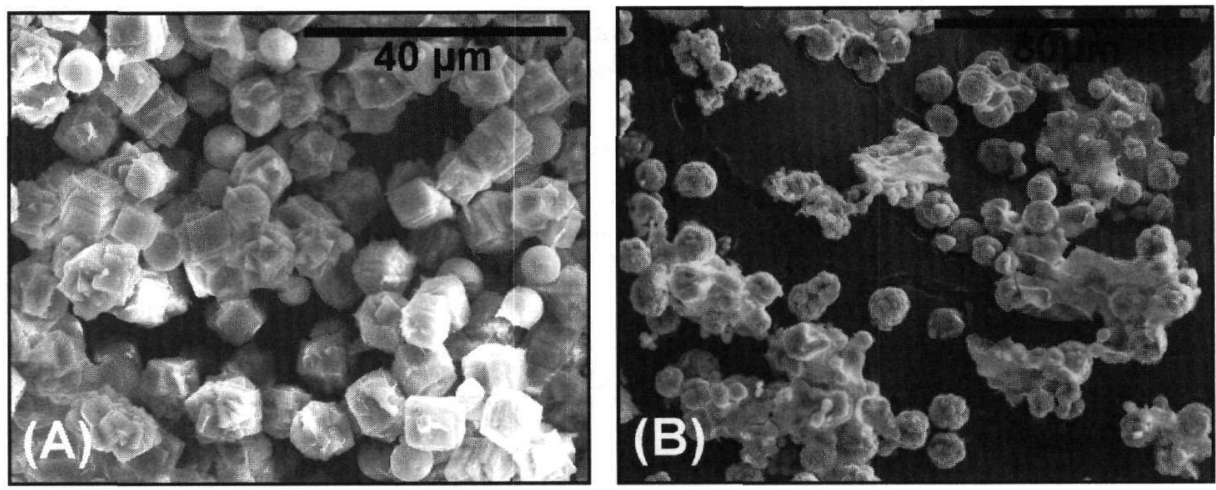

Figure 2 - Two representative SEM images of two different precipitation experiments. (A)

Low concentration of cobalt in initial solution $\left(\mathrm{Ca}^{2+}: \mathrm{Co}^{2+}=17: 1\right)$ where crystallinity is dominating on precipitates surface, and (B) precipitates from solution with $\mathrm{Ca}^{2+}: \mathrm{Co}^{2+}=5: 1$, in which crystals are partially covered by the low-crystallinity phase

The low-crystallinity phase that precipitated in experiments within a wide $\mathrm{Co}^{2+} / \mathrm{Ca}^{2+}$ range of aqueous solutions was characterized by FTIR spectroscopy. In order to study the evolution and the chemical composition of this phase, a group of 6 different precipitates were analyzed. The analysis of the samples revealed a concurrent precipitation of crystalline $(\mathrm{Ca}, \mathrm{Co}) \mathrm{CO}_{3}$ solid phases with a Co-rich matter of low crystallinity that was designated to a cobalt carbonate hydrate $\left(\mathrm{CoCO}_{3} \cdot \mathrm{nH}_{2} \mathrm{O}\right)$.

The mole fraction of the crystal phase near the calcium carbonate endmember was determined using the INCA Energy 200 microanalysis system of the scanning electron microscope. For initial solutions high in calcium, the measured solid phase composition did not vary more than \pm 0.05 $\mathrm{XCoCO}_{3}$. In experiments high in cobalt this value increased up to $\pm 0.1 \mathrm{XCoCO}_{3}$ because of the presence of the low-crystallinity phase (Fig. 4). 

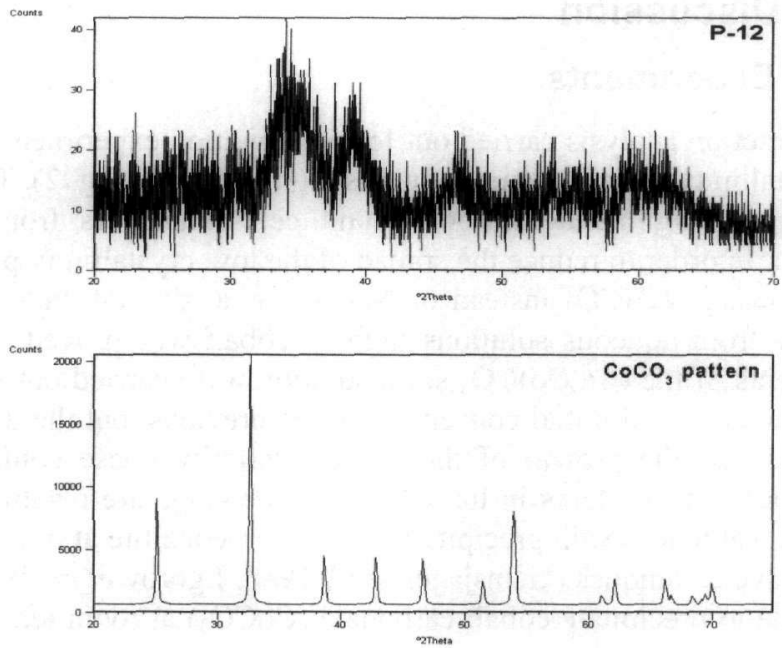

Figure 3 - Diffractogram of the experimental $\mathrm{CoCO}_{3}$ pure endmember $(\mathrm{P}-12)$ in comparison to the spherocobaltite pattern $\left(\mathrm{CoCO}_{3}\right.$ pattern) taken from the PDF database of the $\mathrm{X}$ 'Pert Plus

Table 4 - Unit cell parameters of the precipitates obtained near the Ca-rich side of the solid solution. Numbers in parenthesis indicate the standard deviation

\begin{tabular}{|c|c|c|c|c|}
\hline experiment & $\mathrm{XCoCO}_{3}$ & $\boldsymbol{\alpha}=\mathbf{b}(\AA)$ & $\mathbf{c}(\AA)$ & Vcell $\left(\AA^{3}\right)$ \\
\hline P-1 & 0 & $5.003(1)$ & $17.078(6)$ & $370.2(2)$ \\
\hline P-2 & 0.17 & $5.002(1)$ & $17.063(6)$ & $369.8(2)$ \\
\hline P-3 & 0.21 & $4.9888(9)$ & $17.024(7)$ & $366.9(2)$ \\
\hline P-4 & 0.28 & $4.9876(4)$ & $17.017(3)$ & $366.6(1)$ \\
\hline P-5 & 0.31 & $4.9824(6)$ & $16.980(5)$ & $365.1(2)$ \\
\hline P-6 & 0.37 & $4.972(1)$ & $16.886(6)$ & $361.5(2)$ \\
\hline P-7 & 0.46 & $4.969(1)$ & $16.866(6)$ & $360.6(2)$ \\
\hline
\end{tabular}

For solid phase compositions near the $\mathrm{CaCO}_{3}$ endmember, the $\mathrm{X}$-ray diffraction patterns were indexed in the $R \overline{3} c$ space group of the Hexagonal-Scalenohedral class and the cell parameters were calculated (Table 4) using the computer program X'Pert Plus version 1.0. The solid phase precipitated as pure calcium carbonate clearly corresponds to calcite ( $\mathrm{P}-1$ experiment), while the rest of the patterns exhibit a continuous shift towards higher $2 \theta$ angles as cobalt mole fraction increases. As expected, for different solid solution compositions, cell parameters and volume decrease with increasing Co content (Figure 5). This tendency is in agreement with the smaller radius of $\mathrm{Co}^{2+}(0.72 \AA)$ compared to that of calcium $\mathrm{Ca}^{2+}(0.99 \AA)$. 


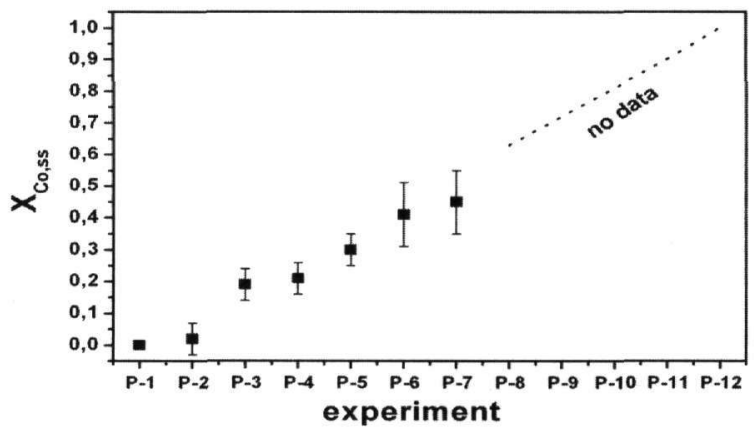

Figure 4 - Measured cobalt mole fraction of the solid phase $\left(\mathrm{XCoCO}_{3}\right)$
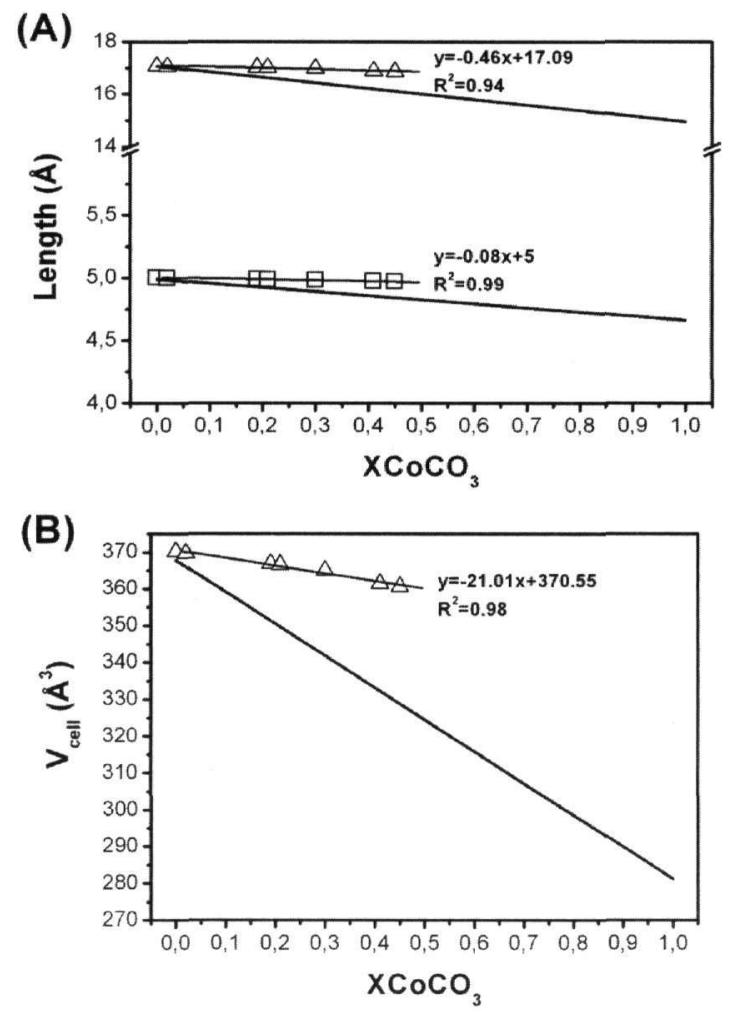

Figure 5 - Variation of refined (A) unit cell parameters and (B) unit cell volumes of precipitates against the mole fraction of $\mathrm{CoCO}_{3}$. In figure (A) squares correspond to parameter a, and triangles to c. Bold, solid lines are the lines joining the cell parameters of the pure endmembers

\subsection{Gel Experiments}

One of the main features of silica hydrogel experiments is the high supersaturation obtained, allowing the study of system behaviour under nonequilibrium conditions. In relation to precipitation experiments, larger crystals were formed allowing (1) the definition of crystal's chemical evolution and (2) the description of different crystal forms that could be possibly developed. 

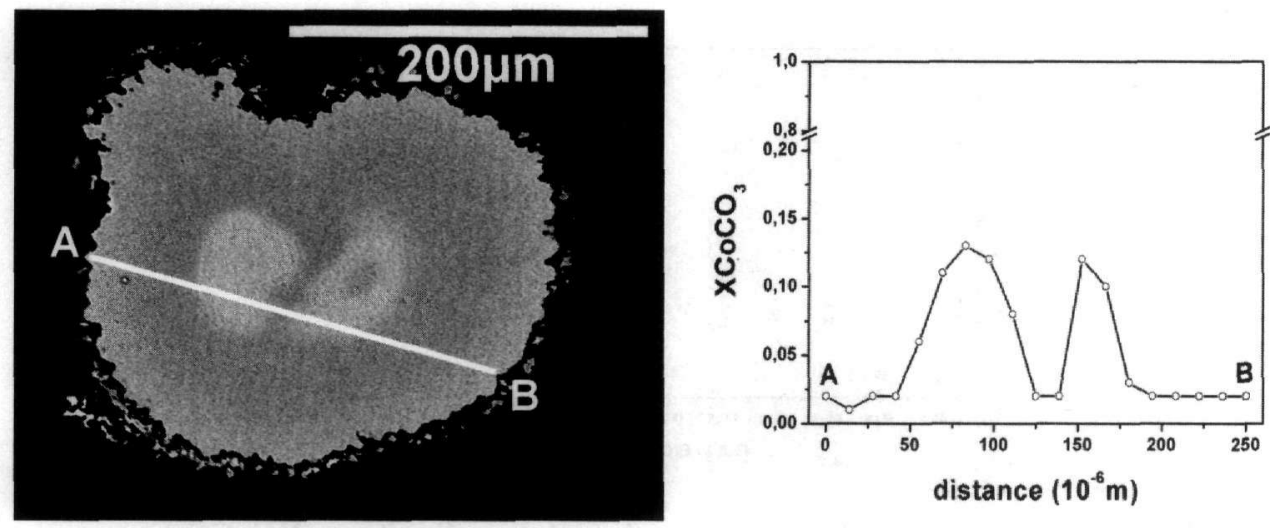

Figure 6 - A SEM-BSE image showing a solid extracted from a gel experiment with $\mathrm{Ca}^{2+}: \mathrm{Co}^{2+}=1: 1.7$ in initial solution. As shown in the compositional profile at the right, along the line A-B, crystals exhibit a clear compositional zoning with two cobalt-rich cores surrounded by a calcium-rich area

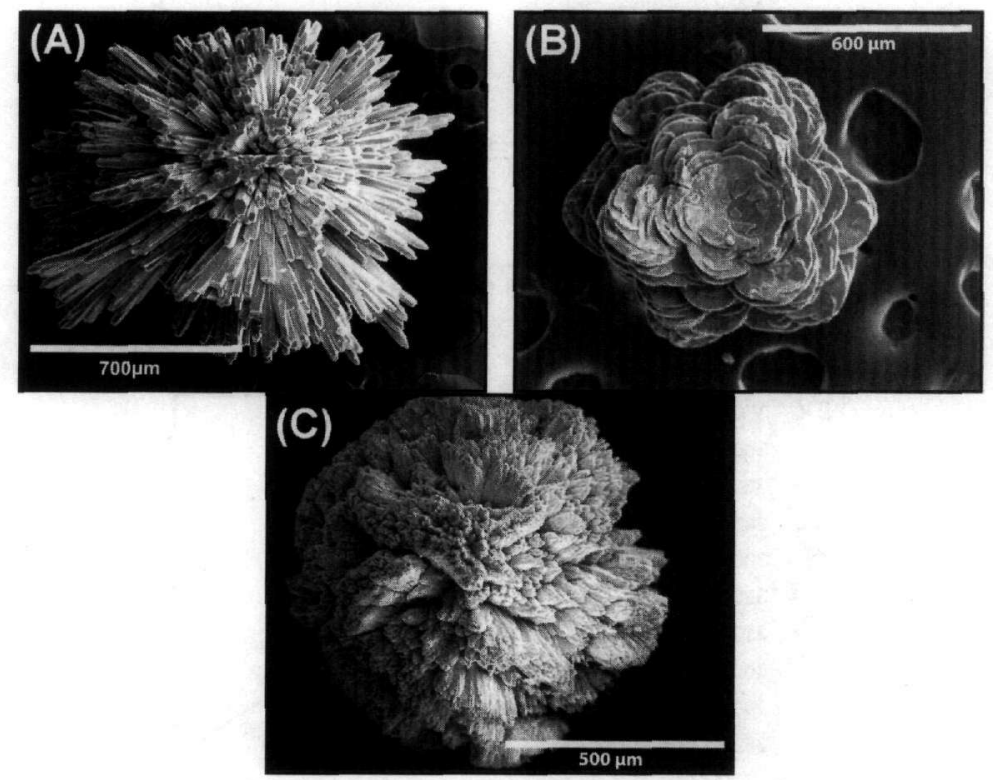

Figure 7 - Scanning electron microscope images showing the different morphologies obtained for different initial concentration of calcium and cobalt. Ratio of $\mathrm{Ca}^{2+} / \mathrm{Co}^{2+}$ in initial solution decreases from 10:1 in (A), to 1:1 in (B), and finally to $1: 5$ in (C)

In all the experimental sets followed, crystals are enriched in $\mathrm{Ca}$ with the mole fraction of calcium carbonate $\left(\mathrm{XCaCO}_{3}\right)$ always above 0.95 , as calculated using the SEM-EDS analysis. Referring to experiments with initial concentration of $\mathrm{Ca}$ equals to zero, no crystals were observed in gel column at the time at which the experiments stopped. As cobalt incorporates in a small proportion into the lattice of formed $\mathrm{CaCO}_{3}$, even if it is present in high concentrations in aqueous solutions, the existence of a miscibility gap between the end-members of the solid solution is of high possibility. This comes in agreement with previous studies of this system. According to Palache (Palache et al. 1951), in natural solids the range of $\mathrm{Co}^{2+}$ miscibility in calcite varies around $2,7 \%$ at $50{ }^{\circ} \mathrm{C}$. In the same work, the excess free energy of mixing parameter was estimated to be around 4.12 , which indicates a positive excess free energy of mixing and suggests the presence of a 
miscibility gap in the system. Also, Goldsmith et al. (1965), studying the ternary system $\mathrm{CaCO}_{3}$ $\mathrm{MgCO}_{3}-\mathrm{CoCO}_{3}$ found that at $600{ }^{\circ} \mathrm{C}$, about $5 \mathrm{~mol} \% \mathrm{CoCO}_{3}$ is soluble in calcite.

Despite the fact that the composition of the solid solution is very close to pure calcite, some of the crystals are revealing a compositional profile with a clear compositional zoning: a $\mathrm{CoCO}_{3}$-rich core surrounded by $\mathrm{CaCO}_{3}$-rich regions (Fig. 6). This fact can be easily explained by the solubility product constants of the two endmembers. Spherocobaltite $(\operatorname{logKsp}=-9.98)$ is about one and a half order of magnitude less soluble than calcite $(\operatorname{logKsp}=-8.47)$, thus cobalt-rich carbonate crystallizes before $\mathrm{CaCO}_{3}$ occupying the central part of the crystals. In any case, mole fraction of $\mathrm{CoCO}_{3}$ oscillates around 0.05 , and although it increases in Co-rich sections, it never exceeds the value of 0.2 supporting the hypothesis of a wide miscibility gap in the system.

Examination of the crystals grown in the gel experiments through a scanning electron microscope shows a wide variety of crystal morphology as a function of different $\mathrm{Ca}^{2+} / \mathrm{Co}^{2+}$ ratios in initial solutions. Blocky hexagonal prismatic and needle-like crystals are forming spherulites with the presence of rhombohedra for high ratios of $\mathrm{Ca}^{2+} / \mathrm{Co}^{2+}$ (Fig. 7A). For equal concentrations of $\mathrm{Ca}^{2+}$ and $\mathrm{Co}^{2+}$ in the initial solution, crystal morphologies are dominated by rose-like multicrystals (Fig. 7B). Crystallization from solution high in $\mathrm{Co}^{2+}$ and low in $\mathrm{Ca}^{2+}$, produces also spherulites of broken or not very well formed crystals (Fig. 7C).

\section{Conclusions}

Precipitation experiments carried out in room temperature and pressure only produced crystals near the $\mathrm{CaCO}_{3}$ endmember of the solid solution. For $\mathrm{Ca}^{2+} / \mathrm{Co}^{2+}$ values below $17: 1$ a cobalt-rich phase of low crystallinity was precipitating, and near the $\mathrm{CoCO}_{3}$ endmember was dominating in precipitates preventing the definition of mole fraction and unit cell parameters at this side of the solid solution. An FTIR spectroscopy assigned the low-crystallinity matter to a cobalt carbonate hydrate $\left(\mathrm{CoCO}_{3} \cdot \mathrm{nH}_{2} \mathrm{O}\right)$. Crystals of the solid solution that were grown under conditions of supersaturation in gels were Ca-rich $\left(\mathrm{XCoCO}_{3} \approx 0.03\right)$ with a Co-rich core $\left(\mathrm{XCoCO}_{3} \approx 0.15-0.2\right)$. The crystal morphologies developed in those experiments exhibit a wide variety of forms (spherulites, rose-like multicrystals etc.) depending mainly on initial solution concentration. No crystals were extracted from the gel experiments referring to the pure $\mathrm{CoCO}_{3}$ endmember of the solid solution.

The presence of a miscibility gap in the system is the key factor in order to characterize the solid solution. Therefore, it is obligatory to study the thermodynamic properties of the system, and this can be achieved only by eliminating the presence of the low-crystallinity phase near the Co-rich side of the solid solution. Crystals that have grown in gel exhibit various morphologies that possibly correspond to the other two polymorphs of $\mathrm{CaCO}_{3}$, that is to say aragonite and vaterite.

\section{Acknowledgments}

This work was supported by the Marie Curie European Network "Mineral-fluid Interface Reactivity" (European Commission, contract MEST-CT-2005-021120).

\section{References}

Almelo, B.V., 1999. X'Pert Plus v. 1.0. Program for Crystallography and Rietveld Analysis, Philips Analytical.

Andara, A.J., 2004. Físico-Química y Pautas de Cristalización de Soluciones Sólidas de Sustitución Aniónica. Sistemas $\mathrm{BaSeO}_{4}-\mathrm{BaSO}_{4}-\mathrm{H}_{2} \mathrm{O}$, $\mathrm{CaSeO}_{4}-\mathrm{CaSO}_{4}-\mathrm{H}_{2} \mathrm{O}$ y $\mathrm{CaMoO}_{4}$ - $\mathrm{CaWO}_{4}-\mathrm{H}_{2} \mathrm{O}$, Ph.D. Thesis, Universidad de Oviedo. 
Braybrook, A.L., Heywood, B.R., Jackson, R.A., and Pitt, K., 2002. Parallel computational and experimental studies of the morphological modification of calcium carbonate by cobalt, Journal of Crystal Growth. 243(2).

Dullien, F.A.L., 1979. Porous Media - Fluid Transport and Pore Structure.

Egorov, V.M., Ikornikova, N.Yu., and Lobachev, A.N., 1976. Preparation and study of the spherocobaltite monocrystal solubility under hydrothermal conditions, Journal of Crystal Growth. 36(1), 138-46

Fernández-Díaz, L., Astilleros, J.M., and Pina, C.M., 2006. The morphology of calcite crystals grown in a porous medium doped with divalent cations, Chemical Geology. 225, 314-316.

Freij, S.J., Putnis, A., and Astilleros, J.M., 2004. Nanoscale observations of the effect of cobalt on calcite growth and dissolution, Journal of Crystal Growth, 267(1-2), 288-300.

Gamsjager, H., and Reiterer, F., 1980. Investigation of equilibriums involving carbon dioxide, carbonates and water, Environment International. 2(4-6), 419-24.

Goldsmith, J.R., and Northrop, D.A., 1965. Subsolidus phase relations in the systems $\mathrm{CaCO}_{3}$ $\mathrm{MgCO}_{3}-\mathrm{CoCO}_{3}$ and $\mathrm{CaCO}_{3}-\mathrm{MgCO}_{3}-\mathrm{NiCO}_{3}$, Journal of Geology. 73(6), 817-29.

Henisch, H.K., and Garcia-Ruiz, J.M., 1986. Crystal growth in gels and Liesegang ring formation. I. Diffusion relationships, Journal of Crystal Growth. 75(2), 195-202.

Ikornikova, N.Yu., Egorov, V.M., and Lobachev, A.N., 1975. Spherocobaltite single crystals.

Lauwerys, R., and Lison, D., 1994. Health risks associated with cobalt exposure - an overview, Science of the Total Environment. 150(1-3), 1-6.

Lichtner, P.C., Steefel, C.I., and Oelkers, E.H., 1996. Editors. Reactive Transport in Porous Media, Rev. Mineral., 438pp.

Palache, C., Berman, H., and Frondel, C., 1951. Dana's System of Mineralogy. Vol. II. 7th ed. $1124 \mathrm{pp}$.

Parkhurst, D.L., and Appelo, C.A.J., 2003. User's guide to PHREEQC (Version 2) - A computer program for Speciation, Batch-Reaction, One-Dimensional Transport and Inverse Geochemical Calculations. U. S. Geological Survey Water Resources Investigations Report, U. S. Geological Survey. Washington, DC.

Prieto, M., Fernandez-Gonzalez, A., and Martin-Diaz, R., 2002. Sorption of chromate ions diffusing through barite-hydrogel composites: implications for the fate and transport of chromium in the environment, Geochimica et Cosmochimica Acta, 66(5), 783-795.

Robinson, R.A., and Stokes, R.H., 1959. Electrolyte Solutions. The Measurement and Interpretation of Conductance, Chemical Potential, and Diffusion in Solutions of Simple Electrolytes. 2nd ed. $559 \mathrm{pp}$. 